\title{
Evaluation on the Equity of Traditional Chinese Medicine Resource Allocation in Tianjin
}

\author{
Ning $\mathrm{He}^{1}$ and Yanhui $\mathrm{Nie}^{1, *}$ \\ ${ }^{1}$ School of Management, Tianjin University of Traditional Chinese Medicine, Tianjin, 301617, China \\ *Corresponding author.Email:nieyanhui51@126.com
}

\begin{abstract} institution.

\section{INTRODUCTION}

Allocation of TCM resource is the prerequisite factor of health service. At present, the research on TCM resource is mostly focused on the configuration of health technician which is based on cross-section data. Compared with previous studies, this study is going to conduct a dynamic and comprehensive evaluation by means of the panel data of multiple health resource, and break the former single method of research.
\end{abstract}

This paper aims to provide suggestions for the resource allocation of Traditional Chinese Medicine (TCM) during the 14th Five-Year Plan period by analyzing the fairness degree in Tianjin from 2011 to 2019 . We used descriptive analysis to study the allocation of TCM health resource in different districts of Tianjin, conducted the Gini coefficient and Theil index on the fairness research. Since the geographical equity of TCM resource allocation in Tianjin was lower than its population equity, and the regional difference was obvious, it is suggested to increase financial input in health to underdeveloped areas, include geography as an important factor in health planning, promote the sharing of resource and strengthen the construction of basic TCM

Keywords: Tianjin, Traditional Chinese Medicine, Health resource, Analysis of equity

\section{DATA AND METHODOLOGY}

\subsection{Data Source}

The geographical area and resident population were from Statistical Yearbook in Tianjin. The number of TCM institution and actual bed, as well as health technician were from Health Statistics Data in Tianjin.

\subsection{Research Methodologies}

Develop a descriptive analysis of TCM resource allocation in Tianjin. Calculate the fairness degree of the overall allocation of TCM resource by Gini coefficient and Theil index.

\subsection{Statistical Tools}

Set up a database and conduct descriptive analysis by EXCEL2016.Calculate the Gini coefficient through SPSS25.0. Analyze Theil index through STATA15.1.

\section{DESCRIPTIVE ANALYSIS}

\subsection{Geographical area and population of Tianjin}

The sixteen administrative districts of Tianjin grouped into three group by geography. The geographical area of urban districts is 174.92 square kilometers, the geographical area of districts around the city is 1921.06 square kilometers, and the geographical area of districts in outer suburb is 9580 square kilometers. Table 1 shows the permanent resident population of each region of Tianjin from 2011 to 2019. 
Table 1. The number of permanent resident population in each region of Tianjin (ten thousand people)

\begin{tabular}{|l|c|c|c|c|}
\hline Year & Urban Districts & Districts around the city & Districts in the outer suburb & Summation \\
\hline 2011 & 464.80 & 281.67 & 648.25 & 1394.72 \\
\hline 2012 & 472.10 & 283.02 & 659.02 & 1414.14 \\
\hline 2013 & 490.91 & 293.68 & 687.62 & 1472.21 \\
\hline 2014 & 504.69 & 304.38 & 707.74 & 1516.81 \\
\hline 2015 & 488.12 & 333.56 & 725.27 & 1546.95 \\
\hline 2016 & 492.53 & 337.22 & 732.37 & 1562.12 \\
\hline 2017 & 490.87 & 336.09 & 729.91 & 1556.87 \\
\hline 2018 & 492.93 & 338.81 & 727.86 & 1559.60 \\
\hline 2019 & 493.67 & 339.55 & 728.60 & 1561.83 \\
\hline
\end{tabular}

\subsection{Distribution of TCM Resource in Tianjin}

From 2011 to 2019, the number of TCM institution, actual bed and health technician in all regions of Tianjin has increased significantly, but the growth range varies greatly. As shown in table 2, the increase of TCM institution was larger, the increase of actual bed and health technician was relatively slow, and the largest increase was in exurb districts and districts around the city respectively. The number of TCM institution in urban districts was $89.47 \%$ and the growth rate of the number of actual bed was $54.82 \%$ which were lower than the average growth rate. The growth rate of the number of actual bed in districts around the city was $46.14 \%$ and lower than the average growth rate of $73.87 \%$; the growth rate of health technician in exurb districts was $55.56 \%$ and lower than the average growth rate of $73.43 \%$. Although the growth rate of TCM resource in urban districts is slightly slow, the total amount of TCM resource is much higher than other two areas.

Table 2. Distribution of TCM resource in different districts of Tianjin

\begin{tabular}{|c|c|c|c|c|c|c|c|c|c|c|c|}
\hline \multirow{2}{*}{ Sort } & Area & $\mathbf{2 0 1 1}$ & $\mathbf{2 0 1 2}$ & $\mathbf{2 0 1 3}$ & $\mathbf{2 0 1 4}$ & $\mathbf{2 0 1 5}$ & $\mathbf{2 0 1 6}$ & $\mathbf{2 0 1 7}$ & $\mathbf{2 0 1 8}$ & $\mathbf{2 0 1 9}$ & $\begin{array}{l}\text { Growth } \\
\text { Rate(\%) }\end{array}$ \\
\hline \multirow{4}{*}{ Institution (unit) } & Urban districts & 57 & 62 & 66 & 78 & 92 & 95 & 98 & 101 & 108 & 89.47 \\
\cline { 2 - 13 } & Around-city & 7 & 9 & 12 & 14 & 20 & 22 & 23 & 22 & 25 & 257.14 \\
\cline { 2 - 12 } & Exurb & 14 & 17 & 21 & 24 & 27 & 32 & 38 & 42 & 49 & 250 \\
\cline { 2 - 12 } & Summation & 78 & 88 & 99 & 116 & 139 & 149 & 159 & 165 & 182 & 133 \\
\hline \multirow{4}{*}{\begin{tabular}{c} 
Actual bed (sheet) \\
\cline { 2 - 11 }
\end{tabular}} & Urban districts & 3446 & 3486 & 3923 & 4234 & 4850 & 4893 & 5003 & 5019 & 5335 & 54.82 \\
\cline { 2 - 11 } & Around -city & 635 & 679 & 725 & 740 & 772 & 818 & 862 & 911 & 928 & 46.14 \\
\cline { 2 - 10 } & Exurb & 1043 & 1210 & 1366 & 1742 & 1835 & 1918 & 2013 & 2148 & 2646 & 153.69 \\
\hline \multirow{3}{*}{$\begin{array}{c}\text { Health technician } \\
\text { (person) }\end{array}$} & Summation & 5124 & 5375 & 6014 & 6716 & 7457 & 7629 & 7878 & 8078 & 8909 & 73.87 \\
\cline { 2 - 11 } & Arban districts & 4513 & 5274 & 5303 & 5664 & 6012 & 7700 & 7056 & 7115 & 7944 & 76.02 \\
\cline { 2 - 11 } & Exurb & 830 & 987 & 1041 & 1126 & 1135 & 1232 & 1398 & 1510 & 1751 & 110.96 \\
\cline { 2 - 10 } & Summation & 7742 & 8967 & 2998 & 2917 & 2926 & 3008 & 3091 & 3163 & 3732 & 55.56 \\
\hline
\end{tabular}

There were great differences in capita TCM resource in different regions. Although the number of TCM institution per 10,000 people in districts around the city and exurb districts increased by $250 \%$ from 2011 to 2019 which only increased by $78.47 \%$ in urban districts, but the number of TCM institution per 10,000 people in districts around the city and exurb districts was only 0.07 . The number of actual bed per 10,000 people in urban districts reached to 10.81 , and it in exurb districts exceeded 3 in 2019, while it in districts around the city remained at a low level. In terms of the number of health technician per 10,000 people, districts around the city had the largest growth rate with $74.92 \%$. Although the growth rate of TCM resource in urban districts was slightly slower than it of districts around the city, it's quantity of health technician per 10,000 people in 2019 reached 16.09, while it in districts around the city was only 5.16. As shown in table 3 .

Table 3. Distribution of capital TCM resource in different districts of Tianjin (per 10,000 people)

\begin{tabular}{|c|c|c|c|c|c|c|c|c|c|c|c|}
\hline \multirow{2}{*}{ Sort } & Area & $\mathbf{2 0 1 1}$ & $\mathbf{2 0 1 2}$ & $\mathbf{2 0 1 3}$ & $\mathbf{2 0 1 4}$ & $\mathbf{2 0 1 5}$ & $\mathbf{2 0 1 6}$ & $\mathbf{2 0 1 7}$ & $\mathbf{2 0 1 8}$ & $\mathbf{2 0 1 9}$ & $\begin{array}{l}\text { Growth } \\
\text { Rate(\%) }\end{array}$ \\
\hline \multirow{3}{*}{ Institution (unit) } & Urban districts & 12.26 & 13.13 & 13.44 & 15.46 & 18.85 & 19.29 & 19.96 & 20.49 & 21.88 & 78.47 \\
\cline { 2 - 11 } & Around-city & 0.02 & 0.03 & 0.04 & 0.05 & 0.06 & 0.07 & 0.07 & 0.06 & 0.07 & 250 \\
\cline { 2 - 11 } & Exurb & 0.02 & 0.03 & 0.03 & 0.03 & 0.04 & 0.04 & 0.05 & 0.06 & 0.07 & 250 \\
\hline
\end{tabular}




\begin{tabular}{|c|c|l|l|l|l|l|l|l|l|l|c|}
\hline \multirow{4}{*}{ Actual bed (sheet) } & Urban districts & 7.41 & 7.38 & 8.00 & 8.39 & 9.94 & 9.93 & 10.19 & 10.18 & 10.81 & 45.88 \\
\cline { 2 - 12 } & Around-city & 2.25 & 2.40 & 2.47 & 2.43 & 2.31 & 2.43 & 2.56 & 2.69 & 2.73 & 21.33 \\
\cline { 2 - 11 } & Exurb & 1.61 & 1.84 & 1.99 & 2.46 & 2.53 & 2.62 & 2.76 & 2.95 & 3.63 & 125.47 \\
\hline \multirow{2}{*}{$\begin{array}{c}\text { Health technician } \\
\text { (person) }\end{array}$} & Urban districts & 9.71 & 11.17 & 10.80 & 11.22 & 12.32 & 15.63 & 14.37 & 14.43 & 16.09 & 65.71 \\
\cline { 2 - 11 } & Around-city & 2.95 & 3.49 & 3.54 & 3.70 & 3.40 & 3.65 & 4.16 & 4.46 & 5.16 & 74.92 \\
\cline { 2 - 10 } & Exurb & 3.70 & 4.05 & 4.36 & 4.12 & 4.03 & 4.11 & 4.23 & 4.35 & 5.12 & 38.38 \\
\hline
\end{tabular}

\section{EQUITY ANALYSIS}

\subsection{Equity Analysis based on Gini Coefficient}

Based on the permanent resident population, the Gini coefficient of TCM resource in Tianjin was calculated as shown in table 4. From 2011 to 2019, the Gini coefficient of TCM resource allocation by population decreased in the fluctuation, and all of them were lower than 0.4 which was in a reasonable state. On the whole, the Gini coefficient of health technician was higher than institution and actual bed which indicated that the equity of health technician allocation was lower than institution and actual bed. From the change trend, the Gini coefficient of institution decreased from 0.309 in 2011 to 0.288 in 2019; the Gini coefficient of actual bed decreased from 0.241 in 2011 to 0.218 in 2019; the Gini coefficient of health technician decreased from 0.362 in 2011 to 0.331 in 2019.The Gini coefficient of institution allocation by population fluctuated greatly, with the smallest decrease; the Gini coefficient of actual bed increased slightly during 2016-2017, but then showed a general downward trend; although the Gini coefficient of health technician has been decreasing year by year, it was still at a high level and its fairness needs to be enhanced.

Table 4. The Gini coefficient of TCM resource allocation by population in Tianjin

\begin{tabular}{|c|c|c|c|}
\hline Year & Institution & Actual bed & $\begin{array}{c}\text { Health } \\
\text { technician }\end{array}$ \\
\hline 2011 & 0.309 & 0.241 & 0.362 \\
\hline 2012 & 0.309 & 0.237 & 0.360 \\
\hline 2013 & 0.307 & 0.236 & 0.355 \\
\hline 2014 & 0.299 & 0.231 & 0.348 \\
\hline 2015 & 0.307 & 0.228 & 0.340 \\
\hline 2016 & 0.308 & 0.218 & 0.337 \\
\hline 2017 & 0.299 & 0.237 & 0.360 \\
\hline 2018 & 0.287 & 0.236 & 0.355 \\
\hline 2019 & 0.288 & 0.218 & 0.331 \\
\hline
\end{tabular}

Based on geographical area of each region in Tianjin, the Gini coefficient of TCM resource distribution was calculated. As shown in table 5, the Gini coefficient of TCM resource allocation by geography were all higher than the warning line of 0.4 during nine years, showing poor fairness. Among them, the allocation equity of health technician was the worst, with the Gini coefficient exceeded 0.5; the second is TCM institution, with the Gini coefficient approaching 0.5 ; the equity of actual bed allocation is relatively good. From the change trend, the Gini coefficient of actual bed and health technician decreased yearly, and the Gini coefficient of TCM institution decreased from 2011 to 2018, then increased slightly in 2019.From 2011 to 2019, the Gini coefficient of TCM institution decreased from 0.497 to 0.483 , decreased by 0.014 ; the Gini coefficient of actual bed decreased from 0.471 to 0.428 , decreased by 0.043 ; the Gini coefficient of health technician decreased from 0.595 to 0.565 , decreased by 0.03 . The decreasing range of the Gini coefficient of TCM resource was in the order of actual bed, health technician and TCM institution.

Table 5. The Gini coefficient of TCM resource allocation by geography in Tianjin

\begin{tabular}{|c|c|c|c|}
\hline Year & Institution & Actual bed & $\begin{array}{c}\text { Health } \\
\text { technician }\end{array}$ \\
\hline 2011 & 0.497 & 0.471 & 0.595 \\
\hline 2012 & 0.494 & 0.449 & 0.595 \\
\hline 2013 & 0.494 & 0.444 & 0.587 \\
\hline 2014 & 0.493 & 0.438 & 0.585 \\
\hline 2015 & 0.490 & 0.438 & 0.580 \\
\hline 2016 & 0.489 & 0.431 & 0.577 \\
\hline 2017 & 0.484 & 0.439 & 0.572 \\
\hline 2018 & 0.480 & 0.428 & 0.569 \\
\hline 2019 & 0.483 & 0.428 & 0.565 \\
\hline
\end{tabular}

\subsection{Equity analysis based on Theil index}

\subsubsection{Index}

From 2011 to 2019, the total Theil index of TCM institution, actual bed and health technician allocation in Tianjin all decreased to varying degrees, indicating that the overall fairness is improving, and the fairness of TCM resource distribution according to population and geographical area, as well as the fairness between and within different regions is continuously increasing. The change trend of the total Theil index of TCM institution, actual bed and health technician were basically the same, with increasing yearly from 2011 to 2014 and decreasing yearly from 2014 to 2019.In 2019, the largest difference in the allocation of TCM resource was health technician, TCM medical institution, and actual bed in turn. 
Table 6. Total Theil index of TCM health resource allocation in Tianjin

\begin{tabular}{|c|c|c|c|}
\hline Year & Institution & Actual bed & $\begin{array}{c}\text { Health } \\
\text { technician }\end{array}$ \\
\hline 2011 & 0.0319 & 0.0329 & 0.0546 \\
\hline 2012 & 0.0368 & 0.0384 & 0.0587 \\
\hline 2013 & 0.0394 & 0.0413 & 0.0622 \\
\hline 2014 & 0.0421 & 0.0445 & 0.0665 \\
\hline 2015 & 0.0253 & 0.0259 & 0.0499 \\
\hline 2016 & 0.0244 & 0.0248 & 0.0482 \\
\hline 2017 & 0.0236 & 0.0236 & 0.0433 \\
\hline 2018 & 0.0232 & 0.0231 & 0.0391 \\
\hline 2019 & 0.0231 & 0.0222 & 0.0389 \\
\hline
\end{tabular}

\subsubsection{Contribution rate analysis}

From 2011 to 2019, the TCM institution's contribution rate of inter-regional difference was $54.73 \% \sim 71.99 \%$, and the TCM institution's contribution rate of intra-regional difference was $28.01 \% \sim 45.27 \%$; the actual bed's contribution rate of inter-regional difference was $57.51 \%$ $72.66 \%$, and the actual bed's contribution rate of intraregional difference was $27.34 \% \sim 42.46 \%$; the health technician's contribution rate of inter-regional difference was $66.68 \%-75.49 \%$, and the health technician's contribution rate of intra-regional difference was $24.5 \%$ $33.32 \%$.In other words, the contribution rate of interregional difference of the three types of TCM resource are all greater than that of intra-regional difference, indicating the regional difference was the main reason for the unfair allocation of TCM resource in Tianjin, and the fairness in exurb suburb was lower than urban districts and districts around the city. As shown in table 7.

Table 7. Contribution rate of inter-regional and intra-regional differences in allocation of TCM health resource in Tianjin (\%)

\begin{tabular}{|c|c|c|c|c|c|c|}
\hline \multirow{2}{*}{ Year } & \multicolumn{2}{|c|}{ Institution } & \multicolumn{2}{c|}{ Actual bed } & \multicolumn{2}{c|}{ Health technician } \\
\cline { 2 - 7 } & Inter-regional & intra-regional & Inter-regional & intra-regional & Inter-regional & intra-regional \\
\hline 2011 & 0.0175 & 0.0144 & 0.0189 & 0.0140 & 0.0364 & 0.0182 \\
\hline 2012 & 0.0231 & 0.0137 & 0.0249 & 0.0135 & 0.0409 & 0.0178 \\
\hline 2013 & 0.0274 & 0.0120 & 0.0289 & 0.0125 & 0.0454 & 0.0168 \\
\hline 2014 & 0.0303 & 0.0118 & 0.0323 & 0.0125 & 0.0502 & 0.0163 \\
\hline 2015 & 0.0157 & 0.0096 & 0.0161 & 0.0098 & 0.0341 & 0.0158 \\
\hline 2016 & 0.0155 & 0.0089 & 0.0158 & 0.0090 & 0.0341 & 0.0141 \\
\hline 2017 & 0.0153 & 0.0083 & 0.0153 & 0.0083 & 0.0318 & 0.0115 \\
\hline 2018 & 0.0152 & 0.0080 & 0.0151 & 0.0080 & 0.0280 & 0.0111 \\
\hline 2019 & 0.0152 & 0.0079 & 0.0148 & 0.0074 & 0.0279 & 0.0110 \\
\hline
\end{tabular}

\section{RESULTS AND PROBLEMS}

\subsection{The Equity Degree of TCM Resource Allocation Has Been Improved, but the Regional Difference Is Still Obvious}

As the main place to provide TCM service, more than $60 \%$ of TCM institution were located in urban districts which made the TCM service in districts around the city and exurb districts at a low level, also resulted in huge challenge that to provide multi-level and diversified TCM service for residents. The gap between urban and rural areas is large, the overall efficiency is difficult to achieve, and can not meet the needs of rural residents.

\subsection{The geographical equity of TCM resource allocation is lower than the population equity}

The geographical area of urban districts accounts for less than $1.5 \%$ of the geographical area of the whole city, but the number of TCM institution, actual bed and health technician were doubled higher than districts around the city and exurb suburbs. This may be related to the fact that the allocation of health resource is based on the per capita medical and health resource ownership, with little consideration of geographical distribution for a long time[1].

\subsection{Regional Difference Is the Main Reason for the Unfair Allocation of TCM Resource}

Theil index showed that the unfairness of TCM resource allocation in Tianjin was caused by intra-regional difference and inter-regional difference which due to the unbalanced economic development and large population difference among administrative regions[2].The regional allocation of health resource is a comprehensive and complex social 
system engineering, which needs multi-departments to carry out multi-dimensional unified optimization layout.

\section{SUGGESTIONS}

\subsection{Increase Financial Input in Health to Underdeveloped Areas}

Increasing financial input is an important way to solve the gap of regional TCM resource [3].It's necessary to optimize the structure and scale of financial input on the basis of increasing financial input, since rational distribution of health resource fully reflect the fairness of health input, so the main responsibility of the government should be clarified, at the same time the excessively market-oriented pattern of health resource allocation should be broken, and the health policy of primary medical institution should be reasonably guided to invest in the field of TCM.

\subsection{Include Geography As an Important Factor in Health Planning}

In the formulation of regional health planning, in addition to the total population of each district, a scientific system configuration mode should be established according to regional area, population density and other influencing factors [4].While narrowing the between regional difference, we should also take the fairness of internal resource allocation into account. Focusing on intra-regional synergy, allocating and integrating regional TCM resource in accordance with the principles of fairness, rationality and efficiency, so as to drive the coordinated development of the whole region [5].

\subsection{Promote the Sharing of Resource and Strengthen the Construction of Basic TCM Institution}

Improving the internal imbalance of TCM resource should by focusing on promoting the sharing of TCM resource among regions and strengthening the construction of basic TCM institution. It is suggested that the government should integrate the superior resource of each region, adjust the total amount, layout and structure of TCM institution at all levels and various types, and pay attention to creating a fair, just and open competitive environment. Through the establishment of TCM medical association or TCM hospital group, etc., regional medical information collaboration and sharing can be realized to promote TCM institution to give full play to their advantages[6].

\section{CONCLUSION}

Scientific and rational allocation of TCM resource is an important guarantee to improve the quality of social welfare level. In general, the total amount of TCM resource in Tianjin is large, but there are significant differences in the allocation of TCM resource among regions. Influenced by various factors such as economic development level, the allocation of TCM resource was mainly inclined to the economically developed areas, especially the allocation of health technician. The allocation of TCM resource is affected by many factors, and governments at all levels and relevant departments should take comprehensive consideration in the allocation of TCM resource.

\section{REFERENCES}

[1] Yang Fan, Katumba Kenneth Roger, and Griffin Susan." Incorporating health inequality impact into economic evaluation in low- and middle-income countries: a systematic review" Expert review of pharmacoeconomics \& outcomes research. (2021). doi:10.1080/14737167.2021.1954505.

[2] Radinmanesh Maryam, et al." A review of appropriate indicators for need-based financial resource allocation in health systems" BMC health services research 21.1(2021). doi:10.1186/S12913-021-06522-0.

[3] Xinhe Li, Kazunori Kawamura. "Methodology for Real-Time Evaluation of Geographic Health Care Resource Allocation: Iwate Prefectural Hospitals" Science Journal of Business and Management 9.2 (2021). doi:10.11648/J.SJBM.20210902.11.

[4] Zizhao Zhao, et al." Status Quo and Equity of Health Care Resources Allocation in China from 2016 to 2019: An Empirical Analysis" Science Journal of Public Health 9.3 (2021). doi:10.11648/J.SJPH.20210903.15.

[5] Bravo Fernanda, et al. "Optimization-driven framework to understand health care network costs and resource allocation" Health care management science (2021). doi:10.1007/S10729-021-09565-1.

[6] Desarno Joycelyn, et al." Succession Planning Within the Health Care Organization: Human Resources Management and Human Capital Management Considerations." Nurse Leader19.4(2021). doi:10.1016/J.MNL.2020.08.010. 